\title{
Présence de Réa Simon
}

\section{Yves Peyré}

\section{(2) OpenEdition}

Journals

Édition électronique

URL : http://journals.openedition.org/ccs/1437

DOI : $10.4000 /$ ccs. 1437

ISSN : 2558-782X

\section{Éditeur :}

Presses universitaires de Rennes, Association des lecteurs de Claude Simon

\section{Édition imprimée}

Date de publication : 30 août 2018

Pagination : $27-29$

ISBN : $978-2-7535-7489-2$

ISSN : 1774-9425

\section{Référence électronique}

Yves Peyré, "Présence de Réa Simon », Cahiers Claude Simon [En ligne], 13 | 2018, mis en ligne le 30 août 2019, consulté le 20 février 2020. URL : http://journals.openedition.org/ccs/1437 ; DOI : $10.4000 /$ ccs. 1437 


\title{
PRÉSENCE DE RÉA SIMON
}

\author{
Yves PEYRÉ ${ }^{1}$
}

Aussi forte qu'elle ait été en elle-même, l'amitié que j’ai eue pour Réa est indissociable de celle que j'ai nourrie à l'endroit de Claude Simon. Il est tout à fait possible que, si elle n'avait pas été sa femme et sa complice, je ne l'aurais pas connue. Tout a commencé en 1977 quand, pour la première fois, je me suis rendu à leur domicile pour y rencontrer Claude. Le contact fut si plaisant, l'échange si fructueux, que le cérémonial se répéta bien des fois. J'entrais dans l'appartement de la place Monge, tout en haut de l'immeuble, après avoir monté à pied les étages, Réa m’introduisait et je dialoguais avec Claude dans son bureau donnant sur la place et permettant de voir les arbres et la caserne de la Garde Républicaine, deux phénomènes qui avaient du prix à ses yeux. Notre discussion n'était interrompue que par l'arrivée des boissons. Nous parlions histoire et création, aventure personnelle et destin du monde. La littérature bien sûr, l'art non moins, bien des épisodes des deux guerres nous occupaient. Ce fut longtemps ainsi. Une petite dizaine d'années. À un moment que je ne saurais situer (sans doute au-milieu des années 1980), les choses se modifièrent et Réa restait désormais avec nous pour la deuxième partie de notre longue discussion. Je trouvais Réa très sympathique et vive d'esprit, elle était attentive à tout et pour Claude jouait le rôle d'un conseiller avisé: elle dactylographiait ses textes et à tout moment les relisait, elle était en somme un correcteur de haut vol. Ses points de vue sur la littérature et l'art se joignaient aux nôtres pour le plus grand bénéfice de la conversation. Je la connaissais de mieux en mieux, je

1. Yves Peyré est écrivain et bibliothécaire. Il est l'auteur de nombreux ouvrages, parmi lesquels Mythologie, avec des photographies de Claude Simon (Jean-Jacques Sergent, 2001). Il a également dirigé la Bibliothèque littéraire Jacques Doucet, où ont été déposés la plupart des manuscrits et archives de Claude Simon. 
l'appréciais beaucoup (c'était de fait réciproque) et je riais de leurs légères divergences sur tel ou tel point. J'éprouvais beaucoup de plaisir à me rendre place Monge. Mes visites n'étaient pas si fréquentes mais j'en faisais au moins deux chaque année, parfois nettement plus.

Nous nous voyions aussi en dehors, notamment dans des lieux publics, comme le Centre Pompidou ou la Bibliothèque nationale, pour une inauguration, j'avais cette surprise joyeuse de soudain les voir surgir tous les deux, Claude me faisant signe de loin et Réa m'embrassant. Nous devisions tantôt avec Tapiès, tantôt entre nous. De ci de là, c'était lors d'une réception chez des amis, notamment au domicile d'un peintre que nous aimions tous. Ma femme s'était mêlée à nos rencontres. Parfois nous dînions chez eux, parfois ils venaient chez nous. Invariablement la sympathie était là. Réa se mobilisa beaucoup pour un voyage en Grèce que nous devions effectuer avec nos deux fils encore jeunes à l'époque. Elle conseillait, cherchait des adresses, démêlait l'essentiel de l'anecdotique, Claude pondérait ou approuvait, il regardait avec nous la carte, il hochait la tête et Réa s'emballait. À notre retour, le séjour leur fut narré dans le détail et ils étaient enchantés de notre satisfaction profonde. Nous étions tous impatients de nous revoir. Durant les dix dernières années de la vie de Claude, un nouveau protocole se mit en place, nous venions le dimanche après-midi pour passer un long moment avec eux. Claude était ravi de saisir le prétexte de la présence de ma femme pour fumer avec elle des cigarillos qui lui étaient désormais interdits, Réa disait haut et fort que c'était un détournement. Ce fut alors, entre mille impressions partagées, que nous fûmes conduits à intervenir sur le cas à bien des égards brûlant d'un désaccord avec leur éditeur à propos de la mise en pages et plus largement de la présentation du début si nouveau (par sa non-linéarité et sa brisure) du Jardin des Plantes. Claude, totalement incompris, était dans le désarroi, Réa secouée par la révolte. Elle envisageait même une édition à compte d'auteur. Nous leur donnâmes les avis que nous pensions les meilleurs. Cette impression du sens jusque dans la matérialité visible de la page était du plus haut prix, il convenait de s'y tenir et de faire fléchir l'éditeur (en somme de l'amener à comprendre). Sur un autre plan, je dirigeais alors la Bibliothèque littéraire Jacques Doucet (Claude m'avait soutenu lors de ma candidature et Réa avait été une supportrice sans faille), nous fûmes sollicités sur le devenir des archives de Claude, qui, se tournant vers Réa et moi, nous dit que nous devions faire comme nous l'entendions, qu'il serait d'accord. Il avait bien sûr son idée, mais il laissait à Réa le soin de l'assumer et à moi-même de la réaliser, ma femme étant à ses yeux le juge de paix et la conscience de tout 
cela. Nous fîmes au fond comme il voulait et il signa tous les papiers officiels. C'étaient toujours de beaux moments, notre complicité était grande.

Réa aimait nous montrer bien des aspects de son quotidien. Elle était fière de son Soulages et sensible à mon goût pour les statuettes kachina des Hopi qu'ils avaient dans leur salle à manger. Elle m'avait confié, et à ma femme tout autant, le détail de sa vie, elle commentait avec compréhension et empathie les divers moments de celle de Claude. Nous étions très proches. Si nous appelions Claude Simon par son prénom, nous le vouvoyions, Réa nous tutoyait et nous aussi en retour.

Un jour, ce fut une forme de rupture brutale, Claude mourut. Ce fut triste. Je voyais beaucoup Réa. Préserver la mémoire de Claude l'aidait plus que tout à faire face, elle avait une mission à remplir. Je commençais l'exploration des richesses, je les classais par séries: la correspondance, les manuscrits, les livres de Claude, les livres reçus, les dossiers variés, les photographies, etc. J'étais dans le bureau de Claude à quatre pattes devant les tas que je constituais. Réa s'en voulait de me voir autant à la peine, elle louait ma persévérance dans la recherche (qui prit pas mal de temps avec une fréquence d'une journée par semaine). Nous regardions partout et, un après-midi, grimpé sur une échelle, je découvris parmi des choses sans trop d'intérêt deux manuscrits que l'on tenait pour perdus, ils étaient entre deux boîtes au-dessus d'un placard de la cuisine. Ce fut comme une danse d'Indiens. Tout ceci se déroulait dans l'harmonie de nos rapports. J'accompagnais Réa dans quelques démarches. Ce fut un moment heureux et d'une intense fraternité. Nous finîmes par tout sauver de l'essentiel, un peu comme si nous avions remis en place un ample puzzle déconstruit par le temps. Nous nous vîmes encore, à trois désormais. J'eus le cœur serré quand Réa m’apparut dans un fauteuil roulant. Ce n'était plus le moment de courir au bistrot d'en face pour un café et une discussion aussi importante que traversée de drôlerie. Réa avait eu une vie riche, autant auprès de Kostas Axelos que de Claude Simon. Elle était invariablement cette jeune fille grecque qui cherchait à s'affranchir des conventions. Elle était libre, d'une rare intelligence, familière et camarade, elle fumait toujours, son regard était profond, elle était agile et incisive, cherchait à rester en accord avec les grandes décisions de principe et savait accepter les aléas de la vie. Elle reste ce sourire derrière ses lunettes, émergeant de ses longs cheveux gris, elle est à jamais cernée par l'auréole du tabac. Sa voix est aussi rauque qu'elle est empreinte de gentillesse. Elle regarde avec attention, cherchant sans fin à voir et à comprendre. 